\title{
Cost and Consequences of Integrated Public Health Campaign in Baglung District, Nepal
}

\author{
Sudarshan Subedi1, Bishnu Prasad Sharma2, Chiranjivi Adhikari1 \\ 1. Lecturer, School of Health and Allied Sciences, Pokhara University \\ 2. Associate Professor, Tribhuvan University, Patan Multiple Campus, Nepal \\ Correspondence: Sudarshan Subedi, School of Health and Allied Sciences, Pokhara \\ University. subedisudarshan@gmail.com
}

\begin{abstract}
Budget allocated, especially for new pilot program should yield beter health efects than the regular ones. The government of Nepal launched Integrated Public Health Campaign (IPHC), a new type of intervention to make rural and vulnerable communities more aware about basic level health care services and increase their utilization. This paper examines the cost of the campaign and its outcomes in terms of providing awareness, utilization of maternal health services and improving health indicators. The study followed a comparative quasi experimental design, study unit being the household and the campaign. Case and Control village development commitees (VDCS) were selected from the same territory and matched based on the criteria of IPHC and other socio-demographic E health services characteristics. Cost calculation was based on direct method whereas the efectiveness was measured by analyzing the output of campaign between case and control VDC. The total cost of the campaign was NRs. 18, 00,000 with per household cost NRs. 585.93 and per capita cost NRs. 123.11. The awareness level of Free Health Services (FHS), Primary Health Care-Out Reach Centre and Safe Delivery Incentive Program (SDIP) was found to be 3.3, 2.65 and 1.95 times more in people of Case VDC than those of Control VDC. Moreover, there was no signifcant association between implementation of campaign with diferent practices of maternal health viz. Antenatal Care visit, delivery, SDIP and post natal care visit. The campaign was found efective in improving the status of OPD visit, measles, TT2+, growth monitoring of children and vitamin A supplementation to postpartum mothers. The campaign was efective in limited aspects. In case of its continuation, revision is necessary with the introduction of newer and beter approaches.
\end{abstract}

Key words: integrated public health, cost and consequences, sanitary latrine

\section{INTRODUCTION}

In order to make rural and vulnerable communities more aware about basic level health care services and their utilization from diferent perspectives, Ministry of Health and Population (MoHP), Nepal had started a type of interventional program named as Integrated Public Health Campaign (IPHC) which is a holistic model health program 
that includes preventive, promotive, and curative health care, especially focused to the poor, disadvantageous, and marginalized population in an integrated way. Principally, it was targeted to those places that have poor health indicators, setlement with high density of disadvantageous group, history of frequent disease outbreaks, and inaccessibility or limited accessibility to transportation facility. The campaign was conducted in four phases in selected village development commitees (VDCs) of the district in the year 2014. Phase I included the community level interventions such as home visit/household interaction providing information on free medicine, safe delivery and abortion sites, providing transportation allowance for institutional delivery along with free treatment facility for those with cancer, heart and kidney diseases; increasing public awareness on personal and environmental hygiene; and community involvement in health programs, and formation of ward level health commitees and health mother groups. Phase II included the aspects for strengthening Primary Health Care Out-Reach Clinic (PHC-ORC) by providing additional equipment, drugs and supplies. Phase III and IV focused more on curative aspects which included one day health facility level Health Camp and 2 days Comprehensive Specialized Health Camp

respectively $(\mathrm{DHO}, 2012)$. The campaign was targeted mainly to increase the awareness on diferent aspects of free/basic health care services, increase the utilization of health services especially the maternal health and to improve the health indicators of the intervened VDCs.

Resources for the delivery of health services are limited in every country and choices need to be made as to which health services should be fnanced by the government (Brenzel, 1993). From an economics perspective, budget allocated and used for any program, especially for the pilot program should be benefcial in terms of its results or expected health efects (Wilkinson, 1999). As the IPHC is a new approach and considered more than the Essential Health Care Services at below district level, there is need to identify the consequences of it and analyzing the efectiveness of components that were addressed, which may help in deciding how this new program could be implemented in future. This may aid to inform choices about the allocation of government's scarce resources for the beterment of health outcomes (Mauskopf et al., 1998). The overall objectives of the study were to calculate the cost of the campaign; and measure the consequences to analyze its efectiveness in terms of public awareness, utilization of maternal health services and health efects produced in concerned villages. Comparison was made between the IPHC implemented (intervened) and not implemented (non-intervened) VDCs of Baglung district.

\section{LITERATURE REVIEW}

Public health campaigns targeted to the rural population to improve their preventive and curative health practices are common places in developing countries (Clasen 
et al, 2014; Naugle \& Hornik, 2014). These interventions have their respective costs and consequences. Their efectiveness is also mixed in nature. An analysis of the cost efectiveness of the national health communication program conducted in Bangladesh through various media channels indicated that such campaigns were efective in physical terms and were cost efective in enhancing antenatal care, DPT vaccine and measles vaccine. But they have scope for further improvement (Hutchinson, 2006). In contrast, the sanitation program conducted in Odisha, India to prevent diarrhea, soil-transmited helminth infection, and child malnutrition, for instance showed that though the quantitative coverage in constructing toilets were fulflled, but the real success in terms of uptake could not be assumed (Clasen et al, 2014). Other studies have also shown that mass media campaigns have been successful in bringing about positive changes or prevent negative changes in health-related behaviours across large populations (Wakefeld, 2010). A more comprehensive review study conducted by Naugle and Hornik (2014) indicated that mass media campaigns can positively impact a wide range of child survival health behaviors in low- and middle-income countries around the world. However, the authors have warned about publication bias with more successful interventions being published while less successful ones remained unnoticed. Health seeking behavior and health related awareness are determined by a myriad of factors. There exists knowledge gap in the efectiveness of public health campaigns in terms of various health related behavioural indicators.

\section{METHODOLOGY}

This study followed a comparative quasi-experimental design to examine the cost and consequences Integrated Public Health Campaign, a new type of intervention to make rural and vulnerable communities more aware about basic level health care services and increase their utilization. For this purpose, treatment and control VDCs were selected on the basis of similarity of characteristics before intervention. The cost components were systematically identifed and estimated along with the intervention outcomes in terms of providing awareness, utilization of maternal health services and improving health indicators.

The study units were the household (for primary data) and campaign (for secondary data). The sample size for primary data was 150 households for each selected Case (intervened) and Control (non-intervened) VDC. Case and Control VDCs were selected from the same territory and matched based on the criteria defned by the IPHC and other similar characteristics of health services and socio-demographic status based on secondary information (Table 1). 
Table 1: Indicators Matched for Selecting Case and Control VDC

\section{Indicators}

IPHC criteria

Total Population (proportion to district)

Population proportion (Male/Female percentage)

Total Household (proportion to district)

Average $\mathrm{HH}$ size

Sanitary latrine

Disadvantaged population

Under 5 Population

Disabled Population

Literacy Rate

Types of health facility available
Case VDC

Yes

$3859(14.36 \%)$

$43 / 57$

$869(14.12 \%)$

4.4

86.42

61.42

9.32

2.17

70.22

SHP
Control VDC

Yes

$3580(13.32 \%)$

$44 / 56$

838 (13.62\%)

4.2

84.12

63.83

8.24

3.49

72.36

SHP

Note: \pm 3 was considered in matching between case and control.

Primary data includes the awareness on diferent components of campaign and status of utilization of maternal health services by the public. Secondary data includes the cost aspect of campaign and health status (indicators) of concerned VDCs. Household interview schedule and checklist were used as the tools whereas interview with household members and record/document review along with interview with concerned ofcials were adopted as techniques for data collection. In context of some primary data like as to assess the status of awareness on diferent components, scoring was done on the basis of response received from the respondents. For every part of knowledge, three categories were identifed as fully correct (completely known), partially correct (partially known) and incorrect (unknown). Respondents knowing all the listed options kept under frst category, knowing some of the options in second category and knowing none under third category. In some cases where there was a dichotomous response, it was categorized as correct and incorrect.

For secondary data, completed checklist was entered into excel database afer manual editing. Cost related data was analyzed by using mathematical and statistical techniques. Indicators related data was analyzed and described on the basis of HMIS. Cost calculation was based on direct method whereas efectiveness analysis was done by analyzing the outputs of the campaign compared between case and control VDCs. Ethical approval was taken from Nepal Health Research Council. Permission was also taken from District Health Ofce, Baglung to conduct the study. Similarly, Individual consent was taken prior to collection of primary data. 


\section{RESULTS}

The major titles in which the cost incurred are presented Table 2. The total cost of the campaign conducted in fve diferent villages of the district in 2014 was NRs. 1,800,000.

\section{Table 2: Cost Calculation of IPHC}

Title

Total Cost

Per Diem (Travel and daily allowances, TADA)

$522,375.00$

Drugs and Medical Supplies

$387,000.00$

PHC - ORC Equipment and Supplies

$120,000.00$

Orientation Training and Related

$147,650.00$

Promotion and Information, Education and Communication ( IEC)

$78,000.00$

Transportation Related

$137,500.00$

Administrative Expenses

$173,300.00$

Supervision and Monitoring

$120,000.00$

Miscellaneous

$114,175.00$

Total Cost $18,00,000.00$

Cost per case VDCs

$3,60,000.00$

Number of implemented VDCs : 5

Source: Authors' estimation

The total cost of the campaign was incurred in utilizing services equally for all fve villages of the district. Hence, the cost for Case VDC was calculated as NRs. 3, $60,000.00$ Taking the total population of fve VDCs in which the campaign was implemented, per household cost of IPHC was calculated as NRs. 585.93 with per capita NRs. 123.11.

Table 3: Per Household per Capita Cost of IPHC

$\begin{array}{ccccc}\begin{array}{c}\text { Total cost of } \\ \text { IPHC }\end{array} & \begin{array}{c}\text { Household of } \\ \text { IPHC area }\end{array} & \begin{array}{c}\text { Population of } \\ \text { IPHC area }\end{array} & \begin{array}{c}\text { Per HH cost of } \\ \text { IPHC }\end{array} & \begin{array}{c}\text { Per capita cost of } \\ \text { IPHC }\end{array} \\ 18,00,000 & 3072 & 14620 & 585.93 & 123.11\end{array}$

Source: Authors' estimation

The extent of association of awareness/knowledge between case and control is shown in Table 4. 
Table 4: Strength of Association on Awareness/Knowledge between Case and Control

\begin{tabular}{|c|c|c|c|c|c|c|}
\hline \multirow[t]{2}{*}{ Variables } & \multicolumn{2}{|c|}{ VDC Type } & \multicolumn{2}{|c|}{ Exposure Rate } & \multirow[t]{2}{*}{ P-Value } & \multirow{2}{*}{$\begin{array}{l}\text { Odd's } \\
\text { Ratio }\end{array}$} \\
\hline & Case & rol Ca & Contro & & & \\
\hline \multicolumn{7}{|c|}{$\begin{array}{l}\text { Awareness on special FHS for } \\
\text { poor with chronic diseases }\end{array}$} \\
\hline Yes & 31 & 11 & 20.66 & 7.33 & 0.001 & 3.3 \\
\hline No & 119 & 139 & & & & \\
\hline \multicolumn{7}{|l|}{ Knowledge on PHC-ORC } \\
\hline Yes & 38 & 17 & \multicolumn{2}{|c|}{25.3311 .33} & 0.002 & 2.65 \\
\hline No & 112 & 133 & & & & \\
\hline \multicolumn{7}{|l|}{ Knowledge on ANC visit } \\
\hline Correct & 124 & 135 & 85.51 & 90.0 & 0.24 & --- \\
\hline Incorrect & 21 & 15 & & & & \\
\hline \multicolumn{7}{|c|}{ Awareness on ANC Incentive } \\
\hline Yes & 135 & 130 & 90.0 & 86.66 & 0.36 & --- \\
\hline No & 15 & 20 & & & & \\
\hline \multicolumn{7}{|l|}{ Knowledge ANC Incentive } \\
\hline Correct & 61 & 54 & \multicolumn{2}{|c|}{45.1841 .53} & 0.54 & --- \\
\hline Incorrect & 74 & 76 & & & & \\
\hline \multicolumn{7}{|l|}{ Awareness on SDIP } \\
\hline Yes & 101 & 77 & \multicolumn{2}{|c|}{67.3351 .33} & 0.005 & 1.95 \\
\hline No & 49 & 73 & & & & \\
\hline \multicolumn{7}{|l|}{ Knowledge on SDIP } \\
\hline Correct & 88 & 73 & \multicolumn{2}{|c|}{87.1294 .80} & 0.08 & --- \\
\hline Incorrect & 13 & 4 & & & & \\
\hline \multicolumn{7}{|l|}{ Awareness on PNC visit } \\
\hline Yes & 111 & 98 & 74.0 & 65.33 & 0.10 & --- \\
\hline No & 39 & 52 & & & & \\
\hline Knowledge on PNC visit & 44 & 57 & \multirow{2}{*}{\multicolumn{2}{|c|}{39.6358 .16}} & & \\
\hline $\begin{array}{l}\text { Correct } \\
\text { Incorrect }\end{array}$ & 67 & 41 & & & 0.07 & - \\
\hline
\end{tabular}

Note: FHS: Free health service; PNC: post natal care; ANC: antenatal care; SDIP: Safe Delivery Incentive Program

Source: Field Survey (2015)

Analysis showed that there is statistical association between implementation of the campaign with awareness/knowledge on FHS, PHC-ORC and SDIP. The awareness/ knowledge level on FHS, PHC-ORC and SDIP is found to be 3.3, 2.65 and 1.95 times more in the people of Case VDC than those of Control VDC. 
Economic Journal of Development Issues Vol. 23 \& 24 No. 1-2 (2017) Combined Issue S. Subedi, B. P. Sharma and C. Adhikari

Table 5. Strength of Association on Utilization of Maternal Health Services between Case and Control

\begin{tabular}{|c|c|c|c|c|c|c|}
\hline \multirow[t]{2}{*}{ Variables } & \multicolumn{2}{|c|}{ VDC Type } & \multicolumn{2}{|c|}{ Exposure Rate } & \multirow[t]{2}{*}{ P-Value } & \multirow{2}{*}{$\begin{array}{l}\text { Odd's } \\
\text { Ratio }\end{array}$} \\
\hline & Case & Control & Case & Control & & \\
\hline \multicolumn{7}{|l|}{ Practice of ANC visit } \\
\hline Yes & 128 & 124 & 85.33 & 82.66 & 0.5 & --- \\
\hline No & 22 & 26 & & & & \\
\hline \multicolumn{7}{|l|}{ Place of latest delivery } \\
\hline Health Facilities & 70 & 55 & 46.66 & 36.66 & 0.79 & --- \\
\hline Non-Health Facilities & 80 & 95 & & & & \\
\hline \multicolumn{7}{|l|}{ Benefted by SDIP } \\
\hline Yes & 66 & 52 & 94.28 & 94.54 & 0.95 & --- \\
\hline No & 4 & 3 & & & & \\
\hline \multicolumn{7}{|l|}{ Practice of PNC visit } \\
\hline Yes & 80 & 68 & 53.33 & 45.33 & 0.16 & _- \\
\hline No & 70 & 82 & & & & \\
\hline
\end{tabular}

Source: Authors' estimation from feld survey data 2015.

Statistical analysis revealed that there is no signifcant diference between treatment and control VDS in terms of diferent practices of maternal health services viz. ANC visit, delivery, SDIP and PNC visit.

Table 6: Health Efects/Outcomes of VDCs before and afer campaign

Health efects/
Indicators

Health service utilization

Total OPD visit in HFs

Family planning

CPR

Safe Motherhood

ANC 1st

ANC 4th

PNC 1st

Immunization

BCG

DPT-HepB-Polio 3

Measles

TT 2+

Nutrition

Growth monitoring

IFA in pregnancy

Vit. A in postpartum
Case VDC Before Afer Before Afer Case Control

Note: OPD: Out Patient Department; CPR: Contraceptive Prevalence Rate; IFA: Iron

Folic Acid

Source: Field Survey, 2015 
Table 6 revealed that afer the campaign, there was an increment in OPD visit and CPR in case VDC whereas there were improvements in safe motherhood in control VDC. Analysis showed that the campaign was efective in increasing the status of utilization of OPD visit, measles, TT2+, growth monitoring and vitamin A to postpartum mother.

\section{DISCUSSION}

Allocated cost and calculated cost (used-up cost) of the campaign were found to be equal, which signifes that the budget for the campaign was completely used and spent by the concerned authority. The total cost for the campaign was calculated as NRs. 18, 00,000 with per HH cost NRs. 585.93 and per capita cost NRs. 123.11. Maximum cost of the campaign was incurred for Per Diem (travel allowance and daily allowance) for mobilizing adequate number of health workers of diferent categories; followed by drugs and medical supplies that were used especially for two types of health camp.

IPHC, under the components of community intervention has focused on providing awareness and knowledge to people on diferent health aspects and services. Awareness and knowledge are correlated with each other, the former one explaining the status of known or unknown, the later one explaining exactly what is known. Comparative analysis showed that people of the Case VDC were more aware on ANC incentives, SDIP and PNC visit, whereas people of the Control VDC had more knowledge on the same aspects. This implies to the fact that people who are more aware on some aspect may not have more knowledge on the same. Moreover, as the awareness of the people from Case VDC on Special FHS, PHC-ORC and SDIP increased 3.3 times, 2.65 times and 1.95 times respectively post campaign, it can be said that the campaign was

efective only in providing information (making people aware) on those aspects as they have not widely been covered in regular IEC program at health facility level.

Awareness and knowledge on certain subject mater are related with its utilization on most of the cases. In context of utilization of maternal health services, proportions of ANC visit, institutional delivery and PNC visit were found higher in the Case VDC but an equal status was noted in both the Case and Control VDC in the utilization of SDIP. Although the utilization rate on maternal health was found more in the Case VDC, it was not due to implementation of the campaign.

Efectiveness of campaign was gauged on the basis of diferent health outcomes between intervened and non-intervened VDCs. Increment over indicators was found in both the VDCs but with some variations. Despite implementation of the campaign in Case VDC, increment was noted only in OPD visit, CPR, measles for children, TT2 for pregnant women and supplementation of vitamin A to postpartum mothers (5 out 
of 12 indicators). However, the campaign has proven efective in increasing the status of utilization of OPD visit, measles for children, TT2 for pregnant women, growth monitoring for children and supplementation of vitamin A to postpartum mother. Beter status of ANC visit, iron supplementation and PNC visit in the Control VDC revealed that regular health program at below district level are doing well and there is no need to focus on maternal health by such types of campaign.

\section{CONCLUSION}

In this study IPHC was found efective in limited aspects only. It showed its efectiveness in providing information on Free Health Services (FHS), Primary Health Care Outreach Clinic (PHC-ORC), Antenatal Care (ANC) incentive, and Safe Delivery Incentive Program (SDIP) which are generally not encompassed in regular \& extensive IEC activities of Ministry of Health and Population, Nepal. The campaign was not found efective in increasing the utilization of maternal health services. Rather it was found efective in improving the utilization of OPD visit, measles for children, TT2 for pregnant women, growth monitoring for children and supplementation of vitamin A to postpartum mother. Some improvement in the key health indicators by the campaign implied that the utilization of cost has not gone squandered. If IPHC is to be continued, revision and adoption of new and beter approaches are required.

This study recommends that the IPHC campaign should focus in providing information and services on new and special aspects of health care that are not covered by usual program. Cost disbursement should be reviewed and addressed to minimize the high cost related to human resources (per diem, supervision and monitoring) and utilize the cost on community level activities and other supporting activities. Furthermore, an extensive research is necessary to calculate other cost approaches with efectiveness analysis adjacent to the regular cost of health services in the concerned district. Non- availability of baseline information and formal report of the campaign produced by the concerned authority along with absence of relevant researches makes the study narrow and less useful for policy formulation.

\section{Acknowledgements}

We acknowledge the support provided by Institute of Nepal Environment and Health System Development (INEHD) and UNICEF for technical and fnancial support; Dr. Shiva Raj Adhikari and Mr. Vishnu Prasad Sapkota for their appreciable guidance; District Health Ofce (DHO) and Health Facility In-charge of selected VDCs of Baglung district for their technical support in data collection. 


\section{References}

Brenzel, L. (1993). Selecting an essential package of health services using cost-efectiveness analysis: A manual for professionals in developing countries. Population, Health and Nutrition Department Population and Human Resources Sector, The World Bank and the Data for Decision Making Project Department of Population Studies and International Health Harvard School of Public Health.

Clasen, T., Boisson, S., Routray, P., Torondel, B., Bell, M., Cumming, O., ...\& Ray, S. (2014). Efectiveness of a rural sanitation programme on diarrhoea, soiltransmited helminth infection, and child malnutrition in Odisha, India: a cluster-randomised trial. The Lancet Global Health, 2 (11), e645-e653.

DHO. (2012). Concept paper on integrated public health campaign . District Health Ofce, Baglung.

Hutchinson, P., \& Wheeler, J. (2006). The cost-efectiveness of health communication programs: What do we know? Journal of Health Communication ,11(sup2), $7-45$.

Mauskopf, J.A., Paul, J.E., Grant, D.M., \&Stergachis, A. (1998). The role of costconsequence analysis in healthcare decision-making. Pharmacoeconomics,13(3), 277-88.

Naugle, D. A., \& Hornik, R. C. (2014). Systematic review of the efectiveness of mass media interventions for child survival in low-and middle-income countries. Journal of Health Communication, 19 (sup1), 190-215.

Wakefeld, M. A., Loken, B., \& Hornik, R. C. (2010). Use of mass media campaigns to change health behaviour. The Lancet, 376(9748), 1261-1271.

Wilkinson, D. (1999). Cost-beneft analysis versus cost-consequences analysis. Performance Improvement Quarterly, 12, 71-81. 